\title{
A Damage Constitutive Model of Rock Subjected to Freeze-Thaw Cycles Based on Lognormal Distribution
}

\author{
Hang Lin $\mathbb{D}^{D}$, Linyuan Liang, Yifan Chen $(\mathbb{D}$, and Rihong Cao \\ School of Resources \& Safety Engineering, Central South University, Changsha 410083, China \\ Correspondence should be addressed to Yifan Chen; 1051361824@qq.com
}

Received 18 April 2021; Revised 16 June 2021; Accepted 22 June 2021; Published 28 June 2021

Academic Editor: Wei-yao Guo

Copyright (C) 2021 Hang Lin et al. This is an open access article distributed under the Creative Commons Attribution License, which permits unrestricted use, distribution, and reproduction in any medium, provided the original work is properly cited.

\begin{abstract}
The constitutive model of rock is closely connected with the mechanical properties of rock. To achieve a more accurate quantitative analysis of the mechanical properties of rock after the action of freeze-thaw cycles, it is necessary to establish the constitutive models of rock subjected to freeze-thaw cycles from the view of rock damage. Based on the assumption of rock couple damage, this study established a statistical damage constitutive model of rock subjected to freeze-thaw cycles by combining the lognormal distribution, which is commonly used in engineering reliability analysis, and the strain strength theory. Then, the coordinates and derivative at the peak of the stress-strain curve of the rock after the action of freeze-thaw cycles were obtained through experiments to solve the statistical distribution parameters $\mu_{\varepsilon}$ and $S$ of the model, whereafter, the theoretical curves by the established model were compared with the experimental curves to verify the validity of it, which shows a great agreement. Finally, the sensitivity analysis of the statistical distribution parameters was implemented. The results indicate that $\mu_{\varepsilon}$ reflects the strength of the rock, which shows a positive relation, and $S$ stands for the brittleness of the rock, which shows a negative relation.
\end{abstract}

\section{Introduction}

Freeze and thaw effect is widely encountered in cold areas, which shows significant influences on the rock mass when constructing geotechnical engineering. In order to ensure the stability of the projects, in addition to considering the inherent mechanical properties of rock mass, it is also necessary to consider the deterioration of the rock mechanical properties under the low-temperature environment and the repeated freezing and thawing action, which has been a research focus in the field of rock mechanics. Extensive research studies have been carried out on the degradation of rock mechanical properties caused by freeze-thaw cycles. Typically, the changes in the compressive mechanical properties [1-5], shear mechanical properties [6-10], tensile mechanical properties [11-13], and dynamic compressive mechanical properties [14-16] of rocks were studied under the influence of freeze-thaw cycles. Despite these studies providing crucial conclusions about the degradation effect of freeze-thaw cycles on the mechanical properties of rocks, the majority of them still remain in the qualitative stage, which may not be used for accurately predicting the mechanical behaviors of rocks subjected to freeze-thaw cycles. As a result, it is necessary to establish a constitutive model of rock subjected to freezethaw cycles to reflect the mechanical behaviors more precisely.

Since the concept of rock statistical damage constitutive was put forward by combining continuous damage theory and statistical strength theory, it has become an efficient method to studying the rock stress-strain relationships [17-19]. Current damage constitutive models mainly adopt the Weibull distribution to describe the statistical characteristics of rock microunits [20-23], while research evidence indicates that Weibull statistical theory may not apply to quasi-brittle materials such as rock. Comparing with the Weibull distribution, the lognormal distribution, as a classic distribution commonly used in engineering reliability analysis, has a wider applicability. Therefore, on the basis of the previous statistical models, this paper established a statistical damage constitutive model of rock subjected to freeze-thaw cycles based on lognormal distribution, which 
was verified by the comparison between the theoretical curves and experimental curves.

\section{Derivation of the Damage Constitutive Model of the Rock after Freezing and Thawing Action}

2.1. Freeze-Thaw Damage Variable $D_{n}$. There exist multitudinous microdefects (cracks, pores, etc.) inside the rock. The water in these microdefects freezes into ice when the temperature around the rock decreases below $0^{\circ} \mathrm{C}$, causing volume expansion, while it melts into water when the temperature rises above $0^{\circ} \mathrm{C}$, in which progress part of the water will migrate $[24,25]$. Under the repeated action of freeze and thaw, the water in the rock continuously goes through phase transitions and migrates, resulting in the expansion, connection, and destruction of these microdefects in the rock, which ultimately manifests as the deterioration of the macromechanical properties of rock $[26,27]$. Therefore, the degradation of the rock macroscopic mechanical properties can be used to characterize the freezethaw damage variable. Because the elastic modulus of the rock after freeze-thaw cycles is easy to measure and analyze, so this study used the following formula to define the rock freeze-thaw damage variable:

$$
D_{n}=1-\frac{E_{n}}{E_{0}}
$$

where $E_{n}$ is the elastic modulus of the rock after different freeze-thaw cycles and $E_{0}$ is the initial elastic modulus of the rock.

2.2. Damage Variable under Loading $D_{p}$. For a quasi-brittle material such as rock, the strain caused by loading is often used to analyze the rock damage. Due to the rock discontinuity and the random distribution of loadbearing particles, it can be assumed that the strain limit of the rock microunits after the action of freeze-thaw cycles obeys a certain statistical distribution, and the failure occurs when the strain of the microunit exceeds the limit. In order to calculate the damage variable $D_{p}$ of the rock at a certain strain level after the action of freezethaw cycle, the initial number of rock microunits after the action of freeze-thaw cycles was denoted as $N_{0}$, and the failure number of rock microunits under a certain strain level is $N_{p}$. Definition:

$$
D_{p}=\frac{N_{p}}{N_{0}} \text {. }
$$

For the statistical distribution that the strain limit of rock microunits after the action of freeze-thaw cycles obeys, the previous research studies mainly employed the Weibull distribution. However, rock is a kind of quasi-brittle material; due to the obvious characteristic length, the problem of size effect in Weibull statistical theory does not apply to quasi-brittle material [28]. Therefore, this paper intended to select the normal distribution to describe the distribution of the strain limit of the microunits. In general, the strain limit of the rock microunits is greater than 0 . If the normal distribution is directly applied, the negative value is definitely unreasonable. In the structural reliability theory, the lognormal distribution is generally used as the structural resistance probability distribution, so this article finally adopted the lognormal distribution as the statistical distribution of the strain limit. Suppose $\ln \varepsilon \sim N\left(\mu_{\varepsilon}, S^{2}\right)$; then, its probability density function is

$$
f(\varepsilon)=\frac{1}{\varepsilon S \sqrt{2 \pi}} \exp \left[-\frac{\left(\ln \varepsilon-\mu_{\varepsilon}\right)^{2}}{2 S^{2}}\right], \varepsilon \geq 0,
$$

where $\mu_{\varepsilon}$ and $S$ are the statistical parameters of the lognormal distribution.

In the process of the rock microunits, strain increases from 0 to $\varepsilon_{1}$, and the number of the damaged rock microunits is

$$
\begin{aligned}
N_{p} & =N_{0} \int_{0}^{\varepsilon_{1}} f(\varepsilon) \mathrm{d} \varepsilon \\
& =N_{0} \int_{0}^{\varepsilon_{1}} \frac{1}{\varepsilon S \sqrt{2 \pi}} \exp \left[-\frac{\left(\ln \varepsilon-\mu_{\varepsilon}\right)^{2}}{2 S^{2}}\right] \mathrm{d} \varepsilon \\
& =N_{0} \Phi\left(\frac{\ln \varepsilon_{1}-\mu_{\varepsilon}}{S}\right),
\end{aligned}
$$

where $\Phi$ refers to the distribution function of the standard normal distribution.

From formulas (2) and (4), the following formulas can be obtained:

$$
D_{p}=1-\Phi\left(\frac{\mu_{\varepsilon}-\ln \varepsilon_{1}}{S}\right)
$$

\subsection{Damage Constitutive Model of Rock Subjected to Freeze-} Thaw Cycles Based on Lognormal Distribution. The damage variables of the rock subjected to the freeze-thaw cycles and the loading separately were deduced above. According to the generalized equivalent strain principle proposed in [29], taking the damage state of the rock after the action of freezethaw cycles as the reference state and the state of the rock after being loaded as the damaged state, the coupling damage can be gained:

$$
\begin{aligned}
D & =1-\left(1-D_{n}\right)\left(1-D_{p}\right) \\
& =D_{n}+D_{p}-D_{n} D_{p},
\end{aligned}
$$

where $D$ is the total damage variable of the rock under the coupling effect of freeze-thaw cycles and loading.

From formulas (1), (5), and (6), the following formula can be obtained:

$$
D=1-\frac{E_{n}}{E_{0}} \Phi\left(\frac{\mu_{\varepsilon}-\ln \varepsilon_{1}}{S}\right) .
$$

When the rock is not subject to freeze-thaw cycles $\left(E_{n}=E_{0}\right)$, 


$$
D=1-\Phi\left(\frac{\mu_{\varepsilon}-\ln \varepsilon_{1}}{S}\right)=D_{p} .
$$

When the rock is unloaded $\left(\varepsilon_{1}=0\right)$,

$$
\begin{gathered}
\Phi\left(\frac{\mu_{\varepsilon}-\ln \varepsilon_{1}}{S}\right)=1, \\
D=1-\frac{E_{n}}{E_{0}}=D_{n} .
\end{gathered}
$$

According to the Lemaitre equivalent strain principle [30] and the generalized Hooke's law, the constitutive equation of the rock under conventional triaxial compression can be obtained:

$$
\sigma_{1}=E_{0} \varepsilon_{1}(1-D)+2 v_{n} \sigma_{3} .
$$

From formulas (7) and (8), the constitutive equation of freeze-thaw damage of rock based on lognormal distribution is

$$
\sigma_{1}=E_{n} \varepsilon_{1} \Phi\left(\frac{\mu_{\varepsilon}-\ln \varepsilon_{1}}{S}\right)+2 v_{n} \sigma_{3},
$$

where $v_{n}$ is Poisson's ratio of the rock after different freezethaw cycles.

2.4. Determination of Model Parameters $\mu_{\varepsilon}$ and S. As shown in Figure 1, the general compression stress-strain curve of rock after the action of freeze-thaw cycles also includes five stages (the compaction stage of the OP section, the elastic stage of the PA section, the stable expansion section of the $\mathrm{AB}$ section, the unstable and unstable expansion section of the $\mathrm{BC}$ section, and the postpeak stage of the $\mathrm{CD}$ section).

It can be seen from Figure 1 that the stress-strain curve passes the peak point and the derivative at the peak point is equal to zero: (1) $\varepsilon_{1}=\varepsilon_{c}, \sigma_{1}=\sigma_{c}$; (2) $\mathrm{d} \sigma_{1} /\left.\mathrm{d} \varepsilon_{1}\right|_{\varepsilon_{1}=\varepsilon_{c}}=0$.

Then, the following formulas can be obtained:

$$
\begin{gathered}
\sigma_{c}=E_{n} \varepsilon_{c} \Phi\left(\frac{\mu_{\varepsilon}-\ln \varepsilon_{c}}{S}\right)+2 v_{n} \sigma_{3}, \\
\frac{\Phi\left(\left(\mu_{\varepsilon}-\ln \varepsilon_{c}\right) / S\right)-\phi\left(\left(\mu_{\varepsilon}-\ln \varepsilon_{c}\right) / S\right)}{S=0},
\end{gathered}
$$

where $\phi$ is the probability density function of the standard normal distribution:

$$
\phi(x)=\frac{1}{\sqrt{2 \pi}} \exp \left(-\frac{x^{2}}{2}\right), x \in R .
$$

Assuming $X=\left(\mu_{\varepsilon}-\ln \varepsilon_{c}\right) / S$, it can be can obtained that $\left(\sigma_{c}-2 \nu_{n} \sigma_{3}\right) / E_{n} \varepsilon_{c}=\Phi(X)$ from formula (12). Substituting the peak point $\left(\varepsilon_{c}, \sigma_{c}\right)$ of the rock stress-strain curve after different freeze-thaw cycles and different confining pressures, the values of $\Phi(X)$ can be obtained; then, the values of $X$ can be obtained by checking the standard normal distribution function table.

From formulas (12)-(14), the following formula can be obtained:

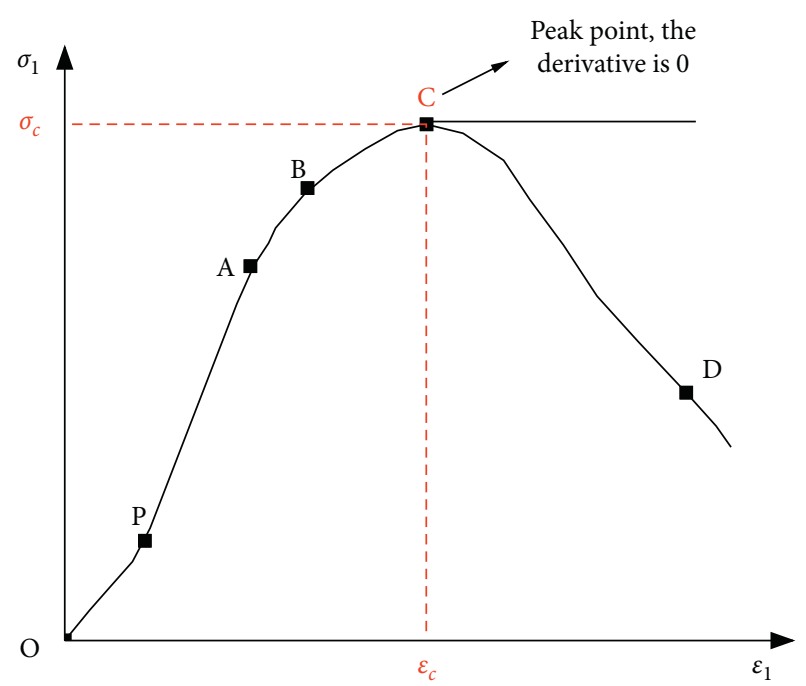

FiguRE 1: The general compression stress-strain curve of rock after the action of freeze-thaw cycles.

$$
\sqrt{2 \pi} \frac{\sigma_{c}-2 \nu_{n} \sigma_{3}}{E_{n} \varepsilon_{c}} S=\exp \left(-\frac{X^{2}}{2}\right) .
$$

Taking the logarithm of both sides of formula (1), we obtain

$$
\ln \left[\sqrt{2 \pi} \frac{\sigma_{c}-2 \nu_{n} \sigma_{3}}{E_{n} \varepsilon_{c}}\right]+\ln S=-\frac{X^{2}}{2} .
$$

From formula (14), the following formulas can be obtained:

$$
\begin{gathered}
S=\exp \left\{-\frac{X^{2}}{2}-\ln \left[\sqrt{2 \pi} \frac{\sigma_{c}-2 \nu_{n} \sigma_{3}}{E_{n} \varepsilon_{c}}\right]\right\}, \\
\mu_{\varepsilon}=X S+\ln \varepsilon_{c} .
\end{gathered}
$$

\section{Model Verification}

The test results of red sandstone triaxial compression after different freeze-thaw cycles conducted in [31] were used to verify the rationality and applicability of the damage constitutive model of the rock subjected to freeze-thaw cycles based on lognormal distribution proposed in this paper.

According to the test results of [31], the model parameters established in this paper were shown in Table 1 . The lognormal distribution parameters under the different freeze-thaw cycles and the different confining pressure were calculated by formulas (17) and (18).

For example, when the number of freeze-thaw cycles $n=5, \sigma_{3}=2 \mathrm{MPa}$. From Table 1 , it can be obtained that

$$
\begin{aligned}
E_{n} & =1.295 \mathrm{GPa}, \\
v_{n} & =0.259, \\
\sigma_{c} & =13.101 \mathrm{MPa}, \\
\varepsilon_{c} & =10.6 .
\end{aligned}
$$


TABle 1: Parameter values of the rock damage constitutive model under different freeze-thaw cycles.

\begin{tabular}{|c|c|c|c|c|c|c|c|c|}
\hline F-T cycles & $\sigma_{3}(\mathrm{MPa})$ & $\phi_{n}\left({ }^{\circ}\right)$ & $E_{n}(\mathrm{GPa})$ & $v_{n}$ & $\sigma_{c}(\mathrm{MPa})$ & $\varepsilon_{c} / 10^{-3}$ & $S / 10^{-3}$ & $\mu_{\varepsilon} / 10^{-3}$ \\
\hline \multirow{3}{*}{0} & 2 & \multirow{3}{*}{38.4} & 1.387 & 0.258 & 14.572 & 11.0 & 0.2144 & 2.6588 \\
\hline & 4 & & 1.628 & 0.255 & 19.652 & 13.0 & 0.3018 & 2.8553 \\
\hline & 6 & & 1.649 & 0.254 & 24.866 & 16.0 & 0.3078 & 3.0644 \\
\hline \multirow{3}{*}{5} & 2 & \multirow{3}{*}{35.8} & 1.295 & 0.259 & 13.101 & 10.6 & 0.2295 & 2.6289 \\
\hline & 4 & & 1.452 & 0.257 & 19.132 & 13.2 & 0.2099 & 2.8386 \\
\hline & 6 & & 1.565 & 0.255 & 24.347 & 17.0 & 0.3499 & 3.1278 \\
\hline \multirow{3}{*}{10} & 2 & \multirow{3}{*}{33.6} & 1.156 & 0.262 & 12.701 & 11.3 & 0.2078 & 2.6821 \\
\hline & 4 & & 1.289 & 0.260 & 18.910 & 14.5 & 0.1950 & 2.9239 \\
\hline & 6 & & 1.325 & 0.259 & 23.519 & 19.2 & 0.3465 & 3.2494 \\
\hline \multirow{3}{*}{20} & 2 & \multirow{3}{*}{30.9} & 0.890 & 0.268 & 11.356 & 12.1 & 0.0985 & 2.6606 \\
\hline & 4 & & 1.066 & 0.264 & 18.100 & 18.0 & 0.2996 & 3.1804 \\
\hline & 6 & & 1.240 & 0.260 & 22.903 & 21.1 & 0.4157 & 3.3369 \\
\hline \multirow{3}{*}{40} & 2 & \multirow{3}{*}{29.2} & 0.710 & 0.277 & 10.570 & 15.2 & 0.2325 & 2.9907 \\
\hline & 4 & & 0.917 & 0.273 & 17.121 & 19.0 & 0.2627 & 3.2253 \\
\hline & 6 & & 0.932 & 0.269 & 21.274 & 24.9 & 0.3832 & 3.5076 \\
\hline
\end{tabular}

Then, $\Phi(X) \quad=\left(\sigma_{c}-2 \nu_{n} \sigma_{3}\right) \quad / E_{n} \varepsilon_{c}=13.101-$ $(2 * 0.259 * 2) / 1.295 * 10.6=0.8789$. By checking the normal distribution table, $X=1.168$.

Substituting it into formula (17), we obtain

$$
\begin{aligned}
S & =\exp \left\{-\frac{1.168^{2}}{2}-\ln \left[\sqrt{2 \pi} \frac{13.101-(2 * 0.259 * 2)}{1.295 * 10.6}\right]\right\} \\
& =0.2295 .
\end{aligned}
$$

Finally, substituting $S=0.2295$ into formula (18), we obtain

$$
\mu_{\varepsilon}=X S+\ln \varepsilon_{c}=1.168 * 0.2295+\ln 10.6=2.6289 .
$$

Then, according to formula (11), the theoretical stressstrain curves of the rock under different freeze-thaw cycles and confining pressure were calculated, which were then compared with the experimental curves. The results were shown in Figure 2, wherein Figures 2(a)-2(e), respectively, represent the comparisons corresponding to the $0,5,10,20$, and 40 cycles of freeze-thaw.

It can be seen from Figure 2 that the theoretical values and the experimental values are relatively close, and the error is within a reasonable range, indicating that the statistical damage constitutive model is reasonable. The proposed model can accurately reflect the elasticity and yield stage of the rock. However, it must be pointed out that the theoretical curve cannot describe the compaction stage of the rock well. This is because the statistical constitutive model assumes that the loaded material are the rock microunits while the pores of the rock are not considered. Therefore, the effect of gas pressure in the pores of the rock during the compaction stage is ignored. In addition, the theoretical curve cannot describe the postpeak stage of the rock. This is because the statistical constitutive model believes that once the strain of rock microunits reaches the strain limit, it is completely damaged and no longer bears any load. In fact, due to the friction between microunits, they still bear a certain residual stress after failure. Thus, this statistical constitutive model is not suitable for the postpeak stage of the rock.

\section{The Physical Meaning of Model Parameters $\mu_{\varepsilon}$ and $S$}

Through carrying out sensitivity analysis of parameters $\mu_{\varepsilon}$ and $S$, respectively, the physical meanings they represent were discussed.

By fixing $E_{n}=2 \mathrm{GPa}, S=1$, and $\sigma_{3}=0 \mathrm{MPa}$ and supposing $\mu_{\varepsilon}=0.8,0.9,1.0,1.1$, and 1.2 , respectively, the different stress-strain curves were shown in Figure 3. It can be seen from Figure 3 that when other parameters remain unchanged, as the parameter $\mu_{\varepsilon}$ increases, the elastic segments of the stress-strain curve basically overlap, the peak strength of the rock increases significantly, and the postpeak curves are roughly parallel. So, it can be considered that $\mu_{\varepsilon}$ reflects the strength of the rock, which is positively related with the strength of the rock.

Similarly, keeping $E_{n}=2 \mathrm{GPa}, \mu_{\varepsilon}=1$, and $\sigma_{3}=0 \mathrm{MPa}$ and supposing $S=0.8,0.9,1.0,1.1$, and 1.2 , respectively, the different stress-strain curves were shown in Figure 4. It can be seen from Figure 4 that when other parameters are fixed, with the continuous increase of the parameter $S$, the elastic segments of the stress-strain curve basically coincide, the peak strength of the rock increases, and the curve after the peak becomes more and more gentle, indicating that the ductility of the rock is enhancing. So, it can be considered that the parameter $S$ represents the brittleness of the rock. As $S$ increases, the ductility of the rock increases while the brittleness of the rock decreases.

In the lognormal distribution, $S$ represents the variance, which means the dispersion degree of the variable. When the value of $S$ is small, the dispersion of the rock strain limit is also small, and the rock is more likely to undergo 


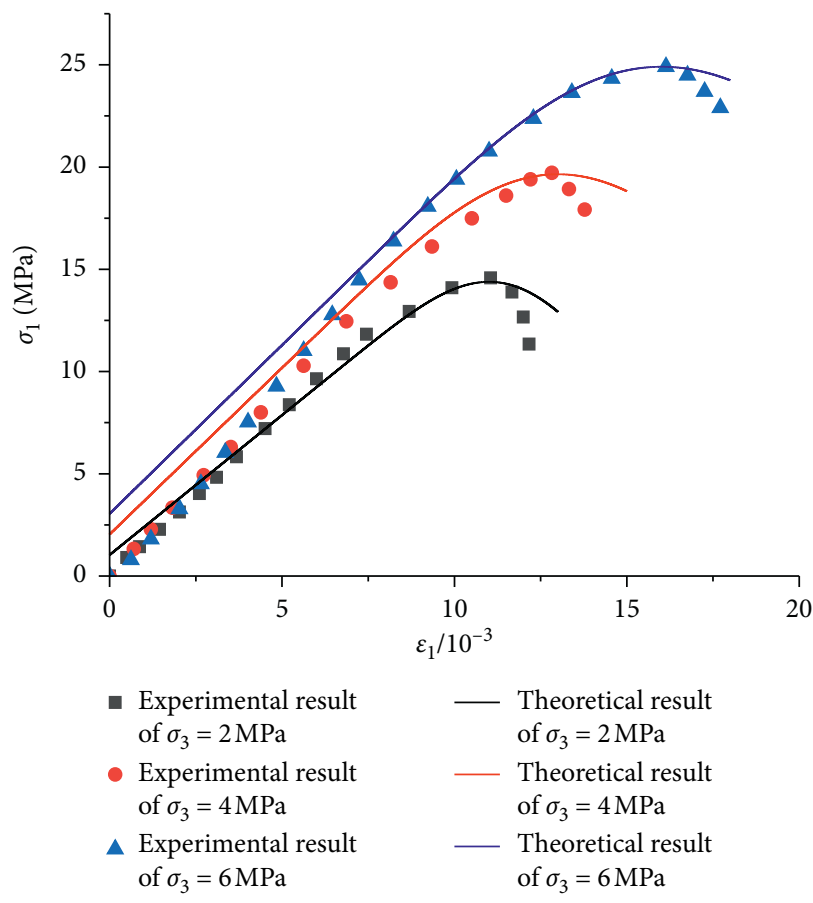

(a)

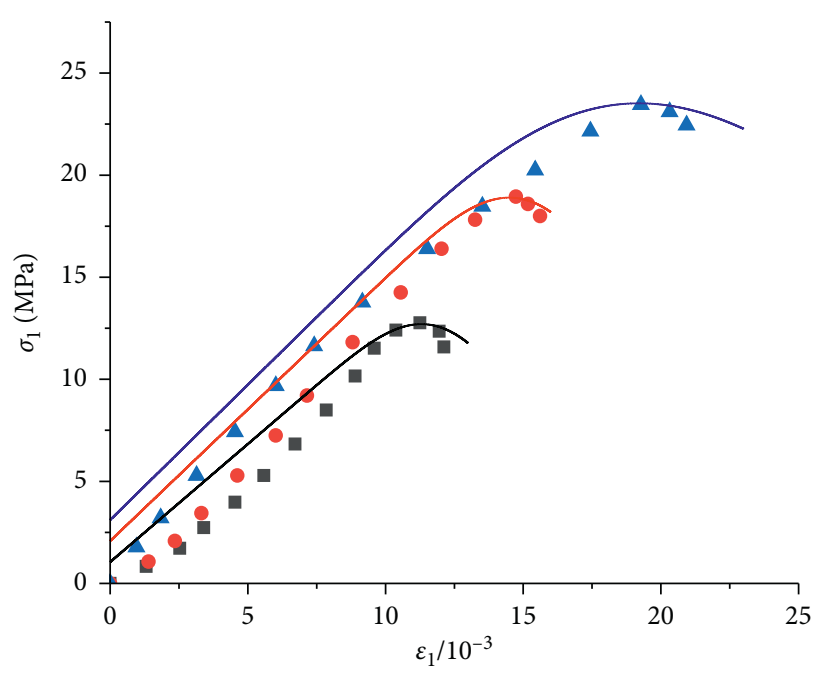

- Experimental result of $\sigma_{3}=2 \mathrm{MPa}$

- Experimental result of $\sigma_{3}=4 \mathrm{MPa}$

$\Delta$ Experimental result of $\sigma_{3}=6 \mathrm{MPa}$

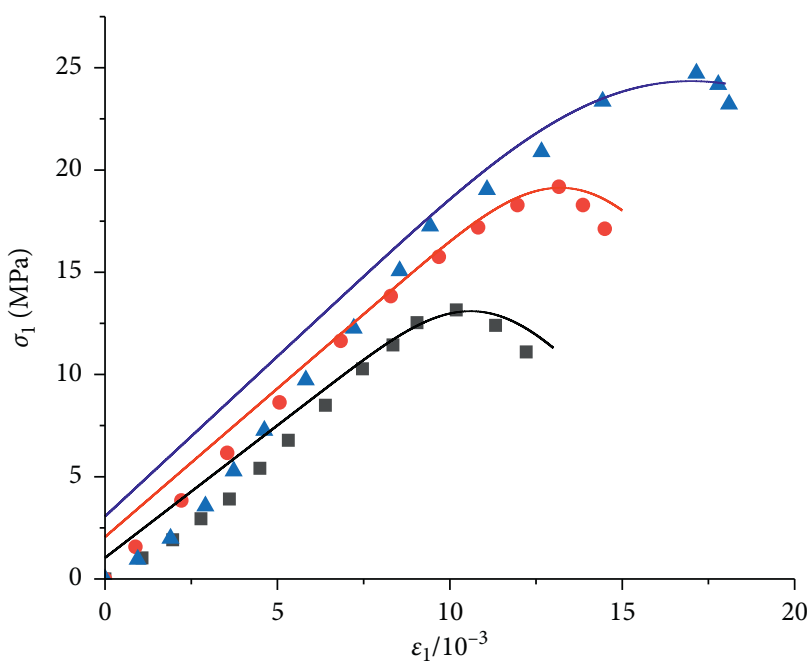

- Experimental result _ Theoretical result of $\sigma_{3}=2 \mathrm{MPa}$ of $\sigma_{3}=2 \mathrm{MPa}$

- Experimental result of $\sigma_{3}=4 \mathrm{MPa}$

- Theoretical result of $\sigma_{3}=4 \mathrm{MPa}$

\. Experimental result of $\sigma_{3}=6 \mathrm{MPa}$

- Theoretical result of $\sigma_{3}=6 \mathrm{MPa}$

(b)

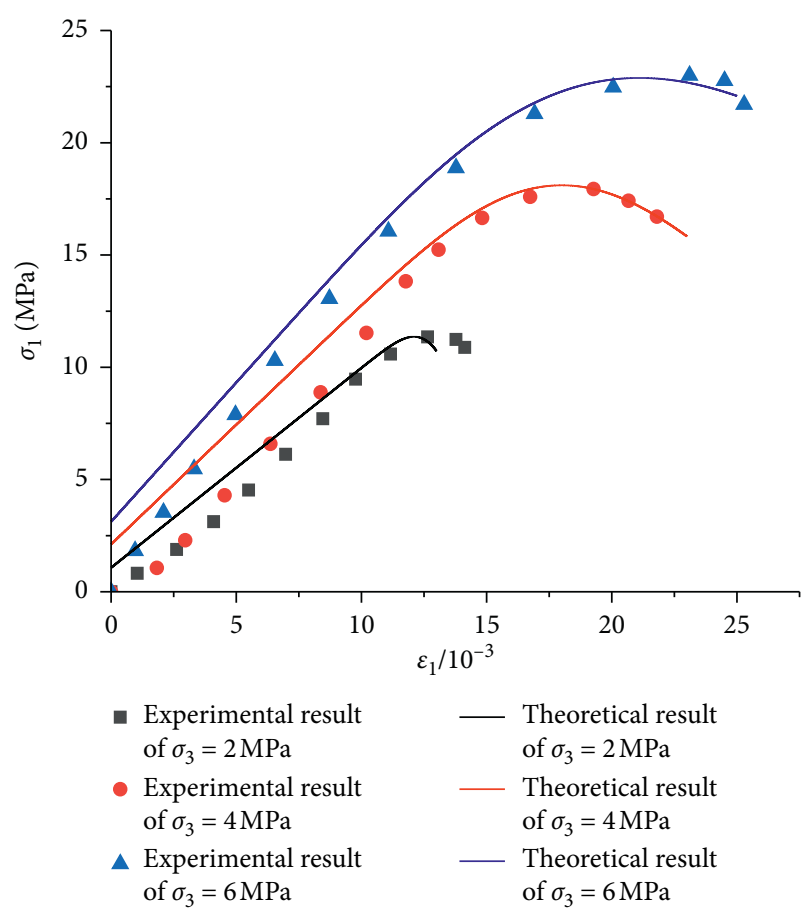

(c)

(d)

Figure 2: Continued. 


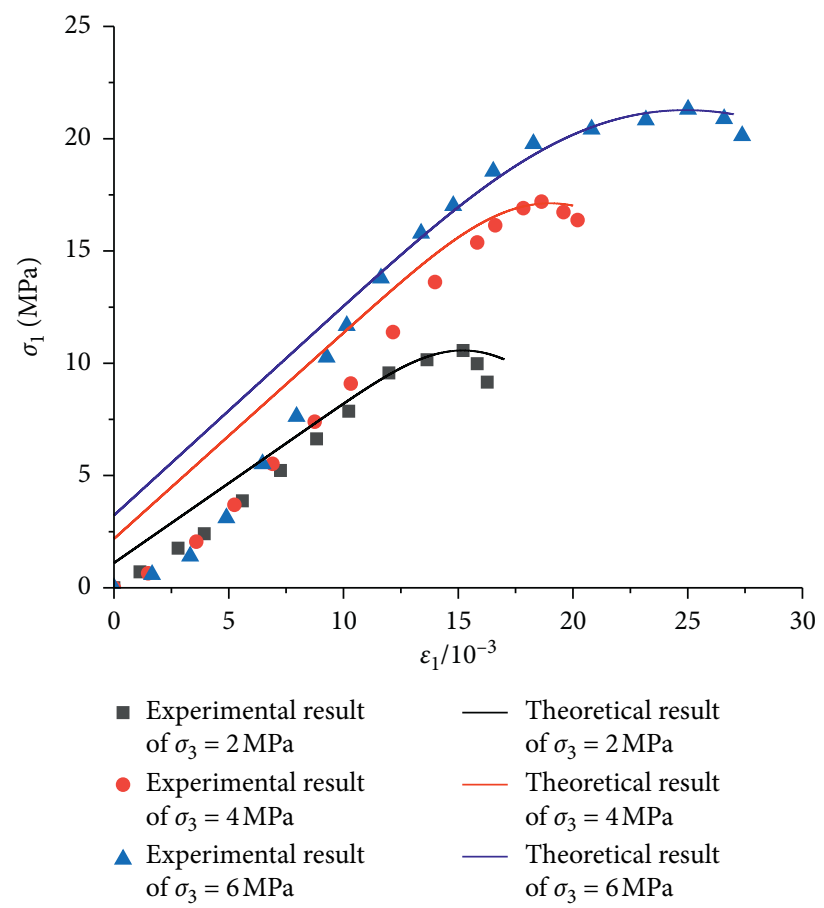

(e)

Figure 2: The stress-strain curves of rock subjected to different freeze-thaw cycles. (a) $n=0$, (b) $n=5$, (c) $n=10$, (d) $n=20$, and (e) $n=40$.

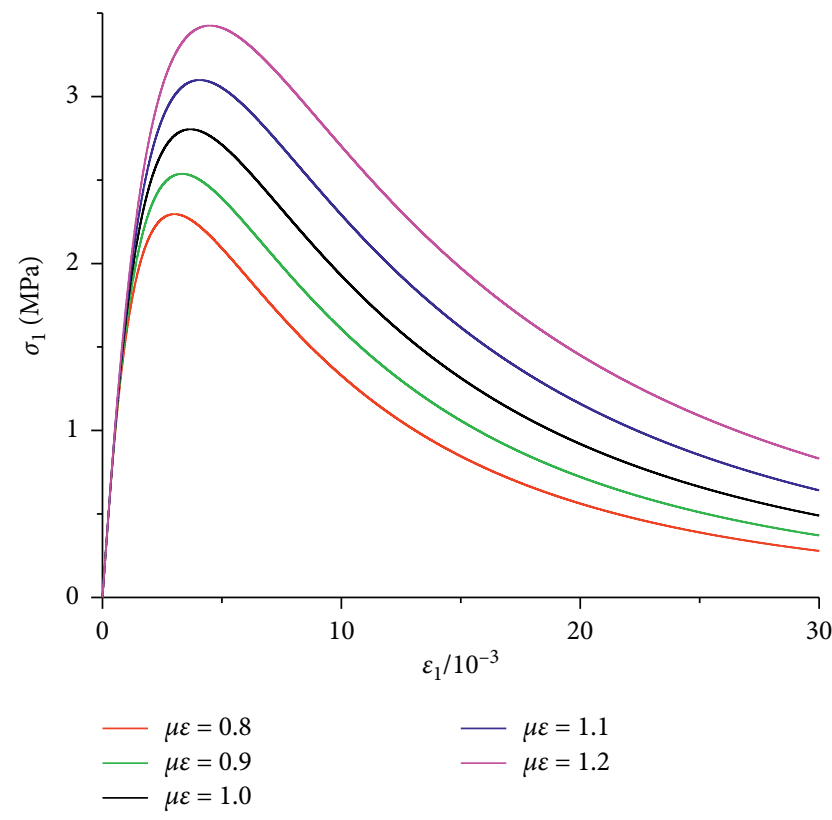

FIGURE 3: The sensitivity analysis of parameters $\mu_{\varepsilon}$.

concentrated failure once the strain reaches the average value of the rock strain limit, causing brittle failure. In the case of large value of $S$, there is still a large part of the rock that has not failed when the strain value reaches the average strain limit, which results in the ductile failure of rock. This is consistent with the previous conclusion drawn by Figure 4.

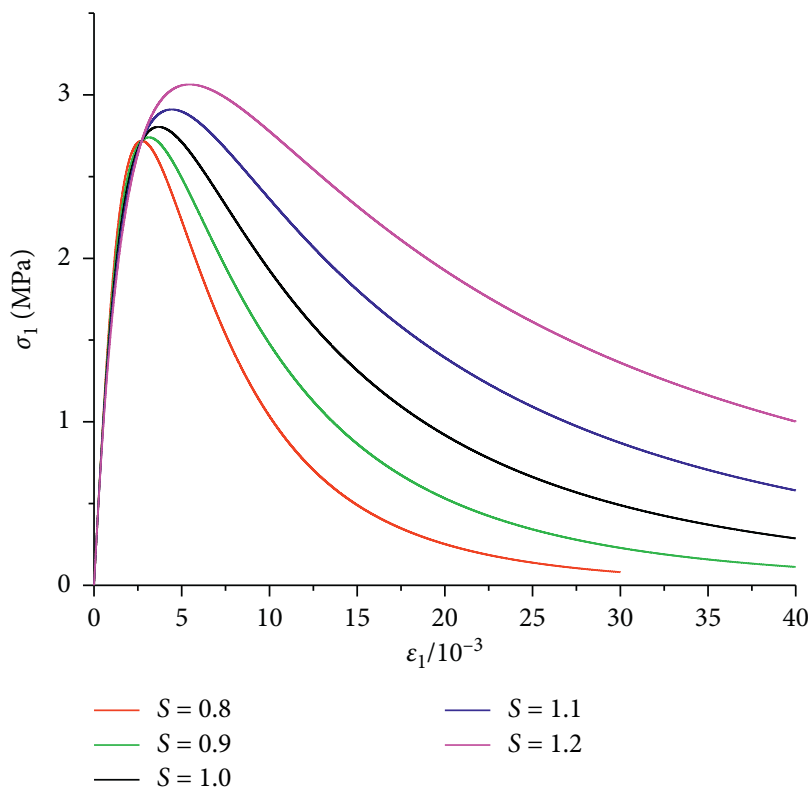

Figure 4: The sensitivity analysis of parameters $S$.

\section{Conclusion}

(1) Through theoretical derivation, this paper established a new statistical damage constitutive model of rock subjected to freeze-thaw cycles based on the lognormal distribution. The model is simple in expression, the parameters are easy to solve, and the stress-strain curve of the rock after the action of 
different freeze-thaw cycles can be obtained, which has strong applicability.

(2) The calculated theoretical curves by established model were compared with the experimental curves, which have similar trends and show a great coincidence, indicating that the statistical damage constitutive model is reasonable and valid. However, it cannot describe the compaction stage and the postpeak stage of the rock very well.

(3) The sensitivity analysis of two lognormal distribution statistical parameters $\mu_{\varepsilon}$ and $S$ have been carried out. The results show that $\mu_{\varepsilon}$ reflects the strength of the rock, which shows a positive relation. $S$ represents the brittleness of the rock. When other parameters remain unchanged, the rock ductility increases while the rock brittleness decreases, as $S$ increases.

\section{Data Availability}

Some or all data, models, or code that support the findings of this study are available from the corresponding author upon request.

\section{Conflicts of Interest}

The authors declare that they have no conflicts of interest.

\section{Acknowledgments}

This work was funded by the project (51774322) supported by National Natural Science Foundation of China and the project (2018JJ2500) supported by Hunan Provincial Natural Science Foundation of China.

\section{References}

[1] X. Fan, X. Jiang, Y. Liu, H. Lin, K. Li, and Z. He, "Local stress distribution and evolution surrounding flaw and opening within rock block under uniaxial compression," Theoretical and Applied Fracture Mechanics, vol. 112, p. 102914, 2021.

[2] S. Huang, Y. Liu, Y. Guo, Z. Zhang, and Y. Cai, "Strength and failure characteristics of rock-like material containing single crack under freeze-thaw and uniaxial compression," Cold Regions Science and Technology, vol. 162, pp. 1-10, 2019.

[3] Y. Lu, X. Li, Y. Han, and J. Wu, "Mechanical properties of rock samples with a single natural weak plane after freeze-thaw action," Cold Regions Science and Technology, vol. 181, Article ID 103179, 2021.

[4] S. Xie, H. Lin, Y. Wang et al., "Nonlinear shear constitutive model for peak shear-type joints based on improved Harris damage function," Archives of Civil and Mechanical Engineering, vol. 20, p. 95, 2020.

[5] Y. Zhao, L. Zhang, W. Wang, W. Wan, and W. Ma, "Separation of elastoviscoplastic strains of rock and a nonlinear creep model," International Journal of Geomechanics, vol. 18, Article ID 4017129, 2018.

[6] J. Mu, X. Pei, R. Huang, N. Rengers, and X. Zou, "Degradation characteristics of shear strength of joints in three rock types due to cyclic freezing and thawing," Cold Regions Science and Technology, vol. 138, pp. 91-97, 2017.
[7] Y. Chen, H. Lin, X. Ding, and S. Xie, "Scale effect of shear mechanical properties of non-penetrating horizontal rocklike joints," Environmental Earth Sciences, vol. 80, p. 192, 2021.

[8] H. Lin, X. Zhang, Y. X. Wang et al., "Improved nonlinear Nishihara shear creep model with variable parameters for rock-like materials," Advances in Civil Engineering, vol. 2020, Article ID 7302141, 15 pages, 2020.

[9] Y. Zhao, L. Zhang, J. Liao, W. Wang, Q. Liu, and L. Tang, "Experimental study of fracture toughness and subcritical crack growth of three rocks under different environments," International Journal of Geomechanics, vol. 20, Article ID 4020128, 2020.

[10] Y. Mo, S. Zuo, Z. Wu, Y. Zhang, and Y. Huang, "Experiment study on in-situ shearing characteristics and crack propagation of shale structural plane," Water Resources and Hydropower Engineering, vol. 52, pp. 134-143, 2021.

[11] T. C. Chen, M. R. Yeung, and N. Mori, "Effect of water saturation on deterioration of welded tuff due to freeze-thaw action," Cold Regions Science and Technology, vol. 38, pp. 127-136, 2004.

[12] C. Liu, D. Wang, Z. Wang, B. Ke, P. Li, and S. Yu, "Dynamic splitting tensile test of granite under freeze-thaw weathering," Soil Dynamics and Earthquake Engineering, vol. 140, Article ID 106411, 2021.

[13] Y. Xu and F. Dai, "Dynamic response and failure mechanism of brittle rocks under combined compression-shear loading experiments," Rock Mechanics and Rock Engineering, vol. 51, pp. 747-764, 2018.

[14] Q. Ma, D. Ma, and Z. Yao, "Influence of freeze-thaw cycles on dynamic compressive strength and energy distribution of soft rock specimen," Cold Regions Science and Technology, vol. 153, pp. 10-17, 2018.

[15] J. Li, R. B. Kaunda, and K. Zhou, "Experimental investigations on the effects of ambient freeze-thaw cycling on dynamic properties and rock pore structure deterioration of sandstone," Cold Regions Science and Technology, vol. 154, pp. 133-141, 2018.

[16] A. Li, Y. Liu, F. Dai, K. Liu, and M. Wei, "Continuum analysis of the structurally controlled displacements for large- scale underground caverns in bedded rock masses," Tunnelling and Underground Space Technology, vol. 97, pp. 1-15, Article ID 103288, 2020.

[17] Y. Liu, F. Dai, L. Dong, N. Xu, and P. Feng, "Experimental investigation on the fatigue mechanical properties of intermittently jointed rock models under cyclic uniaxial compression with different loading parameters," Rock Mechanics and Rock Engineering, vol. 51, pp. 47-68, 2018.

[18] X. Qu, L. Meng, and C. Hao, "Triaxial creep experiment and damage model for slate under different confining pressures and beddings," Water Resources and Hydropower Engineering, vol. 51, pp. 159-167, 2020.

[19] B. Zhang, L. Wang, and S. Zhang, "Study on constitutive model for unloading damage of sandstone under effect of heat-wet cycle," Water Resources and Hydropower Engineering, vol. 49, pp. 162-168, 2018.

[20] H. Zhang, X. Meng, and G. Yang, "A study on mechanical properties and damage model of rock subjected to freeze-thaw cycles and confining pressure," Cold Regions Science and Technology, vol. 174, Article ID 103056, 2020.

[21] Y. Lu, X. Li, and A. Chan, "Damage constitutive model of single flaw sandstone under freeze-thaw and load," Cold Regions Science and Technology, vol. 159, pp. 20-28, 2019.

[22] F. Gao, X. Xiong, C. Xu, and K. Zhou, "Mechanical property deterioration characteristics and a new constitutive model for 
rocks subjected to freeze-thaw weathering process," International Journal of Rock Mechanics and Mining Sciences, vol. 140, Article ID 104642, 2021.

[23] S. Huang, Q. Liu, A. Cheng, and Y. Liu, "A statistical damage constitutive model under freeze-thaw and loading for rock and its engineering application," Cold Regions Science and Technology, vol. 145, pp. 142-150, 2018.

[24] A. Li, F. Niu, C. Xia, C. Bao, and H. Zheng, "Water migration and deformation during freeze-thaw of crushed rock layer in Chinese high-speed railway subgrade: large scale experiments," Cold Regions Science and Technology, vol. 166, Article ID 102841, 2019.

[25] Z. Wang, Z. Zhu, and S. Zhu, "Thermo-mechanical-water migration coupled plastic constitutive model of rock subjected to freeze-thaw," Cold Regions Science and Technology, vol. 161, pp. 71-80, 2019.

[26] M. Deprez, T. De Kock, G. De Schutter, and V. Cnudde, "A review on freeze-thaw action and weathering of rocks," EarthScience Reviews, vol. 203, Article ID 103143, 2020.

[27] X. Zhang, H. Lin, Y. Wang, R. Yong, Y. Zhao, and S. Du, "Damage evolution characteristics of saw-tooth joint under shear creep condition," International Journal of Damage Mechanics, vol. 30, pp. 453-480, 2021.

[28] Z. P. Bazant, "Size effect," International Journal of Solids and Structures, vol. 37, pp. 69-80, 2000.

[29] H. M. Zhang and G. S. Yang, "Research on rock damage model under the coupling action of freeze-thaw and load," Chinese Journal of Rock Mechanics and Engineering, vol. 29, pp. 471-476, 2010.

[30] J. Lemaitre, "How to use damage mechanics," Nuclear Engineering and Design, vol. 80, pp. 233-245, 1984.

[31] C. Peng, "Research on damage and failure characteristics of freeze-thaw loaded rock based on residual strength," Science and Technology University of Xi'an, Xi'an, China, Master Degree, 2017. 